\title{
Analysis and Countermeasures of Human Resource Management in M-SH Company
}

\author{
Sun Ying \\ Shandong Shida Science and Technology Co., Ltd, China University of Petroleum (East China), \\ Dongying 257061, China \\ yanjack@163.com
}

Keywords: human resources; performance assessment; incentives

Abstract: The competition among enterprises is the competition of talents, and the competition of talents in modern enterprises is the competition of human resource management in the final analysis. This paper makes a comprehensive analysis of the human resource management problems of M-SH Company, and puts forward some countermeasures for human resources management of the company.

\section{Introduction}

The competition among enterprises is the competition of talents, and the competition of modern enterprises to talents is in essence the competition of human resources management $[1,2]$. Under the current trend of economic globalization and marketization, human resources is one of the most effective ways for enterprises to gain competitive advantages [3,4]. Therefore, the study of human resources management of enterprises has become a long-term and arduous task for every enterprise.

The M-SH Company described in this paper is a refinery factory. It is state-owned enterprise. M-SH Company has 1 million 500 thousand tons per year of crude oil processing capacity and more than ten sets of refining and chemical production equipment. This paper analyzes the problems in human resource management of the company by using modern human resource management theory. Then the principle of strategic management theory is adopted to solve the problem of human resource management of the company.

\section{Analysis on Human Resource Management of M-SH Company}

\subsection{Present Situation of M-SH Company's Human Resource Management}

The staff of M-SH Company is composed of two parts, staffing of government affiliated institutions and enterprise staff, among which the total number of employees in enterprises is 65\%, the proportion of managers in this part is 34\%, which reflects that there are fewer staff and temporary workers in the operation posts, the administrative staff of the departments and departments are expanding, redundant personnel are heavy and the labor cost is high.

From the composition of the quality of the staff, the age of under 30 is $53.87 \%$, the age above 45 is $11 \%$, the secondary school and above account for $64.08 \%$; The professional title above the 
intermediate level in the managerial staff is $32.2 \%$; As for the worker's technical structure, the intermediate workers and above account for $35.6 \%$, the senior workers and the above account for 15.1\%.

From the human resource management of M-SH Company, the work analysis and work design, as one of the most basic human resource management work, is still in its infancy, which affects the unfolding of follow-up affairs such as work standard formulation, salary survey, performance examination, employee motivation, career design and so on.

\subsection{Analysis of Human Resource Management in M-SH Company}

(1) The development of various elements of the human resource management system is uneven, and there is no organic connection and integration between them.

The payment of M-SH Company is lack of external competitiveness in the labor market, the "economic leverage" adjustment effectiveness of bonus is not significant; Too much attention was payed to education, job qualifications, title and post so that the in payment structure can not fully reflect the actual staff contribution [5]. In recent years, the increase in wages is full of full membership. The praise of the significant contributors has not been carried out alone, and the common reward in the adjustment of the general staff will frustrate their enthusiasm. Middle and upper level incentives are mainly performed in the form of performance contract awards, and the overall motivation is small. At the operational level, there are few incentives for employees and lack of new incentives.

(2) Unsound labor employment

The special affiliation of M-SH Company determines that its labor employment is not perfect, which is embodied in the few qualified labor force, the absolute supply gap of the labor force is large, and the supply of high level talents in the labor market is scarce because of the lack of price attraction. M-SH Company has little room to choose personnel in the market because of its low quality employees.

(3) Problems in performance assessment

The main reasons for the performance assessment of M-SH Company are the problems of performance assessment standards. In the same company, the performance assessment is not enough for the performance of the area, the assessment results in the middle part of the staff are more, the level is not clear. In addition, due to the lack of job standards and job design, the work standards and work contents of different units are not comparable.

(4) Incomplete training content

M-SH Company's current training mainly adopts the method of written test, field skill test and questionnaire, but there is no scientific evaluation standard for the performance improvement and the achievement of the employees after the training. The return rate of the training is also not evaluated.

(5) Lack of cognition on human resource in manager's level

The high level managers of M-SH Company strategically put the development of human resources on the agenda, but in practice, the human resource management of the enterprise is recognized as a general administrative affair. This phenomenon is more common in the human resource management of the state-owned enterprises [6,7]. The flow of staff is not based on the needs of development but administrative. The administrative level and treatment are generally attached importance to in the organization. Like most state-owned enterprises, they attach importance to personnel management activities. It is often targeted at the content of management activities, lacking the concern for people, such as employee satisfaction, employees' understanding of the importance of work and so on. 


\section{Countermeasures of M-SH Company's Human Resource Management}

\subsection{Establish Salary and Welfare System and Employee Incentive Mechanism}

Strategic salary refers to the role of salary in the development of enterprises and its position in the practice of human resource management from a strategic point of view. The role of strategic pay is to motivate employees and retain high performance employees, so as to create higher performance.

Being a industrial company the development strategy of M-SH Company should pay attention to the effect of reducing the cost and the increase of productivity. Therefore, the wage gap between the managers and the operators should not be too large. Based on the development strategy of encouraging employees to innovate and reducing the cost of enterprises, it is necessary to reduce the cost of fixed salary in employees' payment, reduce the proportion of structural wages and skill wages, and increase the proportion of performance and benefit wages.

The existing welfare system of M-SH Company is a fixed benefit. As time goes on, its incentive effect on the psychological level of employees will gradually weaken. It is suggested that M-SH adopt non fixed benefit plan to motivate employees at lower cost. The first feasible non fixed welfare is to carry out the tuition reimbursement system for the extended employees' short-term learning, and to arrange the short-term learning of the less learning employees in the budget range, and reimburse the tuition fees according to the effect of the study. The second non fixed welfare is a variety of health care activities, such as the expert organization pressure management training class to guide employees to reduce psychological pressure, to improve the trend of people's healthy life requirements, to guide employees to carry out weight loss and balanced nutrition plan, to improve health and improve the mental outlook and so on.

\subsection{Improve the Performance Appraisal and Management of the Company}

Performance assessment and management includes two levels of meaning [9]: One refers to the employees in a certain period of time in a certain period of time, the results of a certain number and quality of the analysis, and make an evaluation. The other refers to performance management. Managers should not only make employees clear the goals of performance assessment and measure indicators, but also set up reasonable performance monitoring points and performance information collection and feedback channels, compare the assessment goals and work results, find out the gap and clarify the performance goals and improvement goals of the employees in the next stage.

After carrying out work analysis and work design, post description and post standards can use as the basic source of performance evaluation indicators in M-SH Company. The decomposition of the strategic objectives of the enterprise, such as the M-SH Company's policy objectives as another source of performance indicators, which is used to reflect the contribution of the evaluated posts to the overall objectives of the enterprise. The ultimate goal of this business process is the second source, which is used to reflect the support of the evaluation posts to the endpoint of the business process. Whether the standard of performance evaluation is scientific and reasonable is mainly determined by the above contents. As for M-SH Company's performance evaluation in the future implementation of the overall assessment, each employee is not only evaluated by the superior assessment, but also should have the same level assessment and lower grade assessment. The necessary posts should also increase the staff self-evaluation so that the evaluation results are possible to ensure the comprehensiveness, systematic and objectivity. 


\subsection{Strengthen Staff Training and Development}

Staff training refers to a company's planned implementation of activities that contribute to the ability of the employees to learn and work. These abilities include knowledge, skills, or behavior that plays a key role in the performance of the work. The purpose of training is to enable employees to master the knowledge, skills and behaviors emphasized in training projects, and enable them to apply those items to their daily work [10].

Training new technologies should be adopted to improve the enthusiasm of staff training, such as interactive case training, expert distance training, enterprise network training, simulation training and so on. When adopting the new training technology, we should also evaluate the cost and training effect of the new training technology, and achieve a higher ratio of input to output.

For the annual training program of M-SH Company, the target of return on investment is required and the cost - benefit analysis of training is carried out to facilitate the control of the cost allocation ratio of different training development and management evaluation activities. The difficulty of this activity is the determination of income. M-SH Company is a production enterprise. The feasible method of cost-benefit analysis is to record the change of product quality, the incidence of accident and the increase of yield through the observation method.

\section{Conclusion}

With the development of economic globalization, the competition of human resource management has increasingly become the core competitiveness of enterprises. Through the research on human resource management of M-SH Company, this paper finds out the existing problems in the framework of human resources in the development of the company, and puts forward a targeted solution, which is of great guiding significance to the promotion of the core competitive ability of the company.

\section{References}

[1] Li Zhigang, 2004. Research on the competitiveness of state-owned enterprises, Master's thesis of Southwest Petroleum Institute.

[2] Gao Feng, 2002. Talent competition strategy of state owned enterprises, Human Resource Development of China.

[3] Gao Qingcheng, 2016. The development trend and optimization path of enterprise human resource management under the background of economic globalization, China Labor.

[4] Wang Dazheng, 2000. International talent competition and human resource management, Petroleum Enterprise Management.

[5] Lin Mingcheng, 2015. On how to cope with the human resource flow in the era of wage increase, Business Research.

[6] Wang Weili, 2016. Research on human resource management innovation in the era of knowledge economy, Hebei Enterprises.

[7] Liu Jiahui, 2016. Analysis of the misunderstandings and countermeasures of human resources in enterprises, Management and Technology of Small and Medium Enterprises.

[8] Li Erqing, 2014. Research on human resource management in enterprise culture construction, Shandong Social Sciences.

[9] Wang Yuanyuan, 2017. China's state-owned enterprises performance appraisal countermeasures, Human Resources Management.

[10] Zhao Shuming, 2003. China enterprise group human resource management research, Nanjing University Press. 